\title{
Ventricular interactions and electromechanical dyssynchrony after Ross and Ross-Konno operations
}

\author{
Michal Schäfer, PhD, ${ }^{a}$ Lorna P. Browne, MD, ${ }^{b}$ Johannes C. von Alvensleben, MD, ${ }^{a}$ Max B. Mitchell, MD,
} Gareth J. Morgan, MD, ${ }^{\mathrm{a}} \mathrm{D}$. Dunbar Ivy, MD, ${ }^{\mathrm{a}}$ and James Jaggers, $\mathrm{MD}^{\mathrm{c}}$

\section{ABSTRACT}

Objectives: Ross and Ross-Konno operations are associated with the inherent risk of residual ventricular septal dysfunction and injury to the conduction system. However, comprehensive biventricular functional outcomes on magnetic resonance imaging after Ross and Ross-Konno procedures are unknown. The purpose of this study was to evaluate and compare the degree of electrical and mechanical dyssynchrony using cardiac magnetic resonance imaging in patients late after Ross and Ross-Konno operations.

Methods: Patients following Ross operation $(n=16)$, Ross-Konno operation $(\mathrm{n}=13)$, and healthy controls $(\mathrm{n}=12)$ underwent cardiac magnetic resonance imaging strain deformation analysis to quantify left ventricular (LV) intraventricular dyssynchrony and right ventricular (RV)-LV interventricular dyssynchrony. Mechanical dyssynchrony indices were correlated with the degree of electrical dyssynchrony as assessed by QRS duration, as well as with magnetic resonance imaging-derived biventricular and autograft regurgitation parameters.

Results: Patients in the Ross and Ross-Konno groups had reduced LV global longitudinal strain when compared with controls (both $P$ values $<.01$ ). Both Ross $(P<.05)$ and Ross-Konno $(P<.01)$ groups demonstrated increased RV-LV interventricular dyssynchrony compared with controls. Patients in the Ross-Konno group also had increased septal LV intraventricular dyssynchrony when compared with control and Ross groups (both $P$ values $<.01$ ). The global LV intramechanical dyssynchrony strongly correlated with QRS duration $(R=0.716 ; P<.001)$. There was no association between mechanical dyssynchrony and aortic regurgitation fraction.

Conclusions: Long-term follow-up of patients who underwent Ross and RossKonno operations demonstrates reduced LV global longitudinal strain suggestive of chronically increased afterload independent of autograft function. Additionally, Ross-Konno operation is associated with impaired LV intraventricular mechanics and electrical dyssynchrony. (J Thorac Cardiovasc Surg 2019;158:509-17)

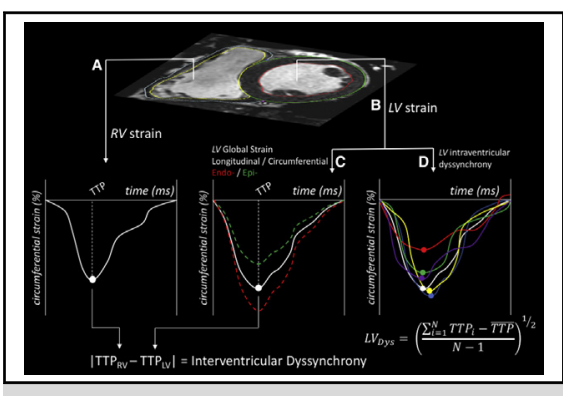

Electromechanical dyssynchrony in patients undergoing Ross and Ross-Konno operations.

\section{Central Message}

In the long-term, Ross-Konno operation is associated with impaired LV intraventricular mechanics and electrical dyssynchrony, yet with preserved ventricular function.

\section{Perspective}

Long-term MRI follow-up of patients after Ross and Ross-Konno procedures shows reduced LV global longitudinal strain that suggests chronically increased afterload and RV-LV interventricular dyssynchrony despite preserved biventricular ejection fraction and normal autograft function.

See Commentaries on pages 518 and 520 .
Surgical replacement of the aortic valve with a pulmonary autograft (ie, Ross operation) has been shown to have excellent long-term clinical outcomes with a major concern being the deterioration of the semilunar valve. ${ }^{1,2}$

\footnotetext{
From the ${ }^{\mathrm{a}}$ Division of Cardiology and ${ }^{\mathrm{c}}$ Section of Congenital Heart Surgery, Heart Institute, and 'Department of Radiology, Children's Hospital Colorado, University of Colorado Denver Anschutz Medical Campus, Aurora, Colo.

Drs Schäfer and Browne contributed equally to this work.

Received for publication Dec 6, 2018; revisions received Feb 6, 2019; accepted for publication Feb 11, 2019; available ahead of print March 28, 2019.

Address for reprints: Michal Schäfer, PhD, Department of Cardiology, Children's Hospital Colorado, 13123 E 16th Ave, Aurora, CO 80045-2560 (E-mail: michal. schafer@ucdenver.edu).

$0022-5223 / \$ 36.00$

Copyright (c) 2019 by The American Association for Thoracic Surgery https://doi.org/10.1016/j.jtcvs.2019.02.057
}

When combined with the repair of subaortic stenosis (ie, Ross-Konno operation), longitudinal outcomes remain encouraging, yet with higher rates of postoperative complications and pulmonary autograft insufficiency. ${ }^{3-5}$ Both procedures are ideal for pediatric and adolescent patients because the pulmonary autograft can accommodate somatic growth after repair. ${ }^{6}$ Unfortunately, both procedures are associated with inherent risk of dysfunction of the ventricular septum due to potential injury to the conduction system, or the first septal perforator artery disruption and distortion of the coronary arteries that may be exacerbated by ventriculoplasty during the Ross-Konno procedure. ${ }^{6,7}$ Long-term results with regard to gold standard magnetic resonance imaging (MRI) assessment of 


$$
\begin{aligned}
& \text { Abbreviations and Acronyms } \\
& \text { LV }=\text { left ventricle } \\
& \text { MRI }=\text { magnetic resonance imaging } \\
& \text { RV }=\text { right ventricle }
\end{aligned}
$$

biventricular function after Ross and Ross-Konno procedures are yet to be determined.

Electromechanical dyssynchrony is increasingly appreciated in patients with complex congenital heart disease and long-term disease processes associated with major myocardial remodeling such as pulmonary hypertension. ${ }^{8-13}$ This is of particular interest considering that responsiveness to cardiac resynchronization therapy in patients with congenital heart disease is associated with immediate improvement in ventricular mechanics. ${ }^{14,15}$ The presence of a bundle branch block and prolonged QRS duration, which serve as primary guideline determinants for cardiac resynchronization, are present on longitudinal follow-up in $13 \%$ to $30 \%$ of patients after Ross and Ross-Konno procedures, respectively. ${ }^{16-18}$ This is not surprising, because electrical and mechanical dyssynchrony are frequently present following the repair of congenital heart disease. ${ }^{11,19}$ However, the majority of previous long-term studies of ventricular function and outcomes after Ross and Ross-Konno procedures have focused on autograft/homograft hemodynamic performance without consideration of electrical dyssynchrony. ${ }^{3,20,21}$ Currently, mechanical deformation analysis and dyssynchrony can be noninvasively assessed from cardiac MRI using featuretracking methods. ${ }^{22,23}$ Previous work has shown an association between intraventricular and interventricular mechanical dyssynchrony with electrical dyssynchrony in repaired tetralogy of Fallot and secondary pulmonary arterial hypertension, but the nature behind the abnormal physiologic interplay between the mechanical and electrical myocardial systems in congenital heart disease requires exploration., ${ }^{9,11}$

The purpose of this study was to evaluate the mechanical and functional biventricular performance using cardiac MRI in children and young adults who underwent a Ross or Ross-Konno operation and compare them with a normal control group, assess the degree of interventricular and intraventricular mechanical dyssynchrony, and investigate whether ventricular mechanical indices are associated with electrical dyssynchrony and autograft regurgitation. We hypothesized that patients who underwent a Ross or Ross-Konno operation would exhibit long-term electromechanical dyssynchrony that would be more prominent in the Ross-Konno patient population due to surgical technique. The improved understanding of biventricular coupling with respect to the electrical conduction abnormalities following surgical repair may improve our long-term clinical follow-up of patients requiring aortic valve replacement and provide better identification of patients who might benefit from cardiac resynchronization therapy.

\section{METHODS}

This study was a retrospective investigation of all patients cared for at Children's Hospital Colorado who underwent Ross or Ross-Konno operations and were referred for cardiac MRI follow-up evaluation for the assessment of biventricular function and autograft or homograft hemodynamic parameter status between 2012 and 2018. Patients with residual atrial or ventricular septal defects were excluded from the analysis. Electrical dyssynchrony was evaluated by an attending electrophysiology specialist as described previously using 12-lead electrocardiograms that were collected within 1 month of cardiac MRI acquisition. ${ }^{10,11}$ Electrical dyssynchrony was defined by the common consensus guidelines as a QRS duration $z$ score $\geq 2$ for both adult and pediatric populations. ${ }^{24,25}$ Healthy control subjects, with no known cardiovascular disease, were recruited from a prior study investigating the cardiovascular health in patients with type 1 diabetes, where they served as a healthy control group. All participants provided informed consent. This study was part of a Colorado multiinstitutional review board-approved imaging protocol.

\section{Cardiac MRI Analysis}

The cardiac MRI protocol included standard biventricular volumetric and functional assessment, and 2-dimensional phase-contrast flow imaging through the pulmonary autograft in the aortic position and the homograft in the pulmonary position. ${ }^{11}$ All strain-deformation analyses were performed using a CVI42 platform for medical image postprocessing for cardiac magnetic resonance, version 5.9.1 (Circle Cardiovascular Imaging, Calgary, Alberta, Canada). The schematic behind overall postprocessing is depicted in Figure 1. Strain indices derived from the short-axis images stacks were obtained at the base- and midventricular level corresponding to American Heart Association model segments 1 to 12. Collected left and right ventricular (LV and RV) indices included global circumferential strain, which was analyzed comprehensively for the entire myocardium and separately for endocardial and epicardial borders. Similarly, 4-chamber images were analyzed for the RV- and LV-specific longitudinal strain. All endocardial and epicardial contours necessary for segmentation-strain analysis were derived in semiautomatic fashion with manual delineation of respective contours at end diastole and were propagated in automatic fashion through the entire cardiac cycle. Manual corrections to the segmentation algorithm were applied as needed. Mechanical dyssynchrony was analyzed as shown previously by analyzing time-to-peak strain values derived for each specific American Heart Association model segment. ${ }^{11}$ Specifically, interventricular dyssynchrony between RV and LV was analyzed as the absolute time difference between time-to-peak strain values from ventriclespecific global circumferential strain values (Figure 1, $A$ and $C$ ). LV intraventricular dyssynchrony was analyzed by calculating the standard deviation of all time-to-peak values per given myocardial region (Figure 1, D). In this fashion, intraventricular mechanical dyssynchrony was analyzed specifically for the entire LV, basal and midlevel regions, and further for myocardial compartments corresponding to the interventricular septum and the LV free wall.

\section{Statistical Analysis}

All statistical analyses were performed in Prism version 7 (GraphPad Software, La Jolla, Calif). Variables were checked for the distributional assumption of normality using normal plots, in addition to KolmogorovSmirnov and Shapiro-Wilk tests. Demographic, clinical, and ventricular characteristics between all groups were compared using 1-way analysis of variance for normally distributed continuous variables and KruskalWallis test was used for nonnormally distributed variables. Corrections 


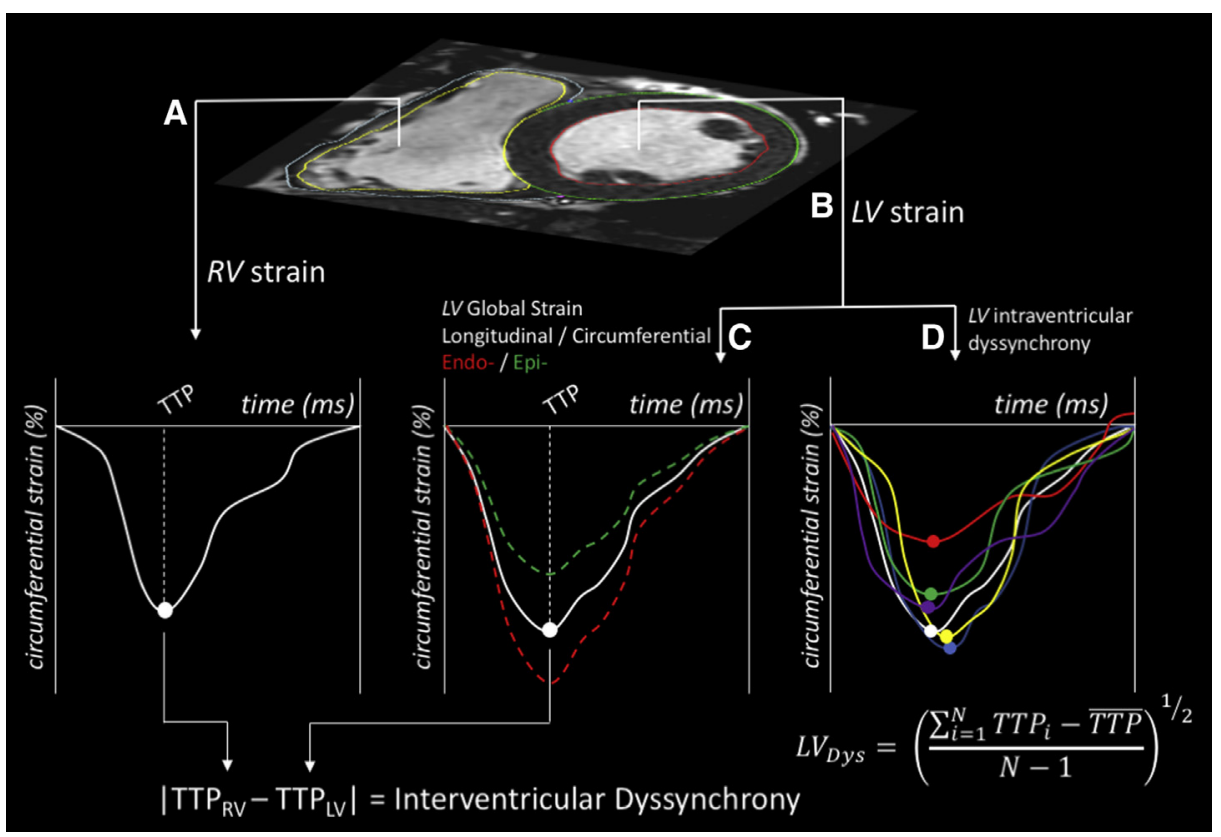

FIGURE 1. Cardiac magnetic resonance imaging postprocessing pipeline for mechanical deformation analysis using feature tracking. A, Endocardial and epicardial contours were delineated for short-axis and long-axis images for each cardiac phase A, Global right ventricle $(R V)$ region-specific longitudinal and circumferential strain curves. B, Global left ventricle $(L V)$ region-specific longitudinal and circumferential strain curves. Global and regional endocardial and epicardial peak strain values were further sampled from the LV. C, To calculate RV-LV interventricular dyssynchrony using respective time-to-peak $(T T P)$ values. D, LV intraventricular dyssynchrony was computed as standard deviation of all time-to-peak values for all considered myocardial segments.

for multiple comparisons using statistical hypothesis testing were Tukey and Dunn tests for analysis of variance and Kruskal-Wallis, respectively. Additional 2-group comparisons were performed using the student $t$ test or Mann-Whitney test as dictated by the nature of the variable. The relationship between the degree of mechanical and electrical dyssynchrony and regurgitation fraction was analyzed by simple linear regression analysis using the Pearson $R$ value. All values are reported as mean \pm standard deviation or median with interquartile ranges.

\section{RESULTS}

Patient characteristics are summarized in Table 1. In total, we identified 16 patients with a history of Ross procedure, 13 patients with a history of Ross-Konno procedure, and 12 control patients. Patients who underwent a Ross procedure were older $(P<.05)$ and had a higher body surface area $(P<.05)$ when compared with the Ross-Konno and control groups. The median time from surgery to cardiac MRI was 10.2 years in the Ross group and 9.7 years in the Ross-Konno group, with no statistical difference between them.

With regard to the status of the conduction system, 6 patients $(38 \%)$ in the Ross group and 11 patients $(85 \%)$ in Ross-Konno group met the criteria for electrical dyssynchrony with significantly higher incidence in Ross-Konno group $(P=.010)$. Patients after Ross-Konno operation had significantly longer QRS duration when compared with the Ross group (126 $\pm 22 \mathrm{~ms}$ vs $104 \pm 17 \mathrm{~ms}$; $P<.001)$. In the Ross group, there was 1 patient $(6 \%)$ with right-bundle branch block and 1 patient (6\%) with left-bundle branch block, whereas in the Ross-Konno group there were 6 patients $(46 \%)$ with right-bundlebranch block and 2 patients with left-bundle-branch block $(12 \%)$.

\section{Cardiac MRI Hemodynamic Parameters}

Standard cardiac MRI derived volumetric and functional hemodynamic parameters are depicted in Table 1. There were no intergroup differences in LV volumes, yet patients in Ross and Ross-Konno groups had decreased ejection fraction when compared with the control group $(54 \% \pm 7 \%$ and $55 \% \pm 4 \%$ vs $60 \% \pm 5 \% ; P<.05)$. Patients in the Ross group had slightly decreased heart rate when compared with both control and Ross-Konno groups, yet without statistical significance. All considered mechanical deformation indices are independent of the position within the actual cardiac cycle, and therefore no further adjustments with respect to heart rate were applied. With respect to the RV, only the Ross-Konno group had increased indexed end-diastolic volumes with controls $\left(126 \pm 34 \mathrm{~mL} / \mathrm{m}^{2}\right.$ vs $\left.91 \pm 11 \mathrm{~mL} / \mathrm{m}^{2} ; P<.05\right)$, and increased indexed endsystolic volume in comparison to controls $\left(67 \pm 28 \mathrm{~mL} / \mathrm{m}^{2}\right.$ vs $\left.39 \pm 28 \mathrm{~mL} / \mathrm{m}^{2} ; P<.01\right)$. There was no difference among groups in RV ejection fraction. Lastly, there was no difference in autograft regurgitation fraction between the Ross and Ross-Konno groups. 
TABLE 1. Patient characteristics and standard hemodynamic parameters by subgroup

\begin{tabular}{|c|c|c|c|c|}
\hline $\begin{array}{l}\text { Characteristic } \\
\text { or parameter }\end{array}$ & $\begin{array}{c}\text { Ross } \\
(n=16)\end{array}$ & $\begin{array}{l}\text { Ross-Konno } \\
\quad(n=13)\end{array}$ & $\begin{array}{l}\text { Control } \\
(n=12)\end{array}$ & $\begin{array}{c}P \\
\text { value }\end{array}$ \\
\hline Age (y) & $22(13-27)^{*}, \dagger$ & $14(7-19)$ & $12(10-16)$ & .024 \\
\hline $\begin{array}{c}\text { Body surface } \\
\text { area }\left(\mathrm{m}^{2}\right)\end{array}$ & $1.8 \pm 0.4^{*}, \dagger$ & $1.3 \pm 0.4$ & $1.4 \pm 0.3$ & .003 \\
\hline Female sex & $5(31)$ & $6(46)$ & $5(42)$ & \\
\hline $\begin{array}{l}\text { Time from } \\
\text { surgery }(y)\end{array}$ & $10.2(6.5-14.0)$ & $9.7(6.0-11.3)$ & & .698 \\
\hline $\begin{array}{l}\text { QRS duration } \\
\text { (ms) }\end{array}$ & $104 \pm 17$ & $126 \pm 22$ & & .009 \\
\hline$z$ Score & $1.4(0.2-2.6)$ & $4.2(3.5-6.9)$ & & $<.001$ \\
\hline E-Dys (\%) & $6(38)$ & $11(85)$ & & .010 \\
\hline RBBB (\%) & $1(6)$ & $6(46)$ & & .012 \\
\hline LBBB $(\%)$ & $1(6)$ & $2(12)$ & & .422 \\
\hline Heart rate (bpm) & $65 \pm 7$ & $74 \pm 12$ & $72 \pm 16$ & .088 \\
\hline LVEDVi $\left(\mathrm{mL} / \mathrm{m}^{2}\right)$ & $98 \pm 18$ & $89 \pm 15$ & $98 \pm 23$ & .406 \\
\hline LVESVi $\left(\mathrm{mL} / \mathrm{m}^{2}\right)$ & $45 \pm 12$ & $40 \pm 9$ & $41 \pm 17$ & .542 \\
\hline LVSVi $\left(\mathrm{mL} / \mathrm{m}^{2}\right)$ & $53 \pm 11$ & $52 \pm 8$ & $56 \pm 10$ & .444 \\
\hline LVEF (\%) & $54 \pm 7 *$ & $55 \pm 4$ & $60 \pm 5$ & .046 \\
\hline Autograft RF (\%) & $7(4-20)$ & $5(2-7)$ & & .115 \\
\hline $\operatorname{RVEDVi~}\left(\mathrm{mL} / \mathrm{m}^{2}\right)$ & $106 \pm 22$ & $126 \pm 34^{*}$ & $91 \pm 11$ & .012 \\
\hline RVESVi $\left(\mathrm{mL} / \mathrm{m}^{2}\right)$ & $52 \pm 18$ & $67 \pm 28 \ddagger$ & $39 \pm 8$ & .009 \\
\hline $\operatorname{RVSVi}\left(\mathrm{mL} / \mathrm{m}^{2}\right)$ & $54 \pm 10$ & $57 \pm 10$ & $52 \pm 10$ & .106 \\
\hline RVEF (\%) & $52 \pm 8$ & $48 \pm 8$ & $56 \pm 5$ & .057 \\
\hline
\end{tabular}

Values are presented as mean \pm standard deviation or median (interquartile range). $P$ values represent 1-way analysis of variance or Kruskal-Wallis test for multiple group analyses or $t$ test, Mann-Whitney, or $X^{2}$ for 2-group comparison. E-Dys, electromechanical dyssynchrony; $R B B B$, right bundle branch block; $L B B B$, left bundle branch block; $L V E D V i$, left ventricle end-diastolic volume index; $L V E S V i$, left ventricle end-systolic volume index; $L V E F$, left ventricle ejection fraction; $R F$, regurgitation fraction; $R V E D V i$, right ventricle end-diastolic volume index; RVESVi, right ventricle end-systolic volume index; $R V S V i$, right ventricle stroke volume index; $R V E F$, right ventricle ejection fraction. $* P<.05 . \dagger P<.05$ from Ross-Konno group. $\ddagger P<.01$ with respect to control group.

\section{Ventricular Strain Analysis}

The summary of the ventricular strain analysis is depicted in Table 2. There was no significant difference in evaluated LV global circumferential strain metrics, regardless of the ventricular level. Similarly, there were no differences in RV global circumferential strain metrics. However, significant changes were observed when evaluating the global longitudinal strain. Differences in LV longitudinal strain analysis are depicted in Figure 2. Both Ross and RossKonno groups revealed significantly depressed global LV longitudinal strain when compared with the control group (both $P$ values $<.01$ ). Similarly, the Ross group had decreased longitudinal endocardial strain $(P<.01)$ and epicardial strain $(P<.05)$ when compared with the control group. The Ross-Konno group also had decreased longitudinal endocardial strain when compared with the control group $(P<.05)$, but without any differences in epicardial
TABLE 2. Ventricular strain indices, by subgroup

\begin{tabular}{|c|c|c|c|c|}
\hline Ventricular strain index & $\begin{array}{c}\text { Ross } \\
(n=16)\end{array}$ & $\begin{array}{c}\text { Ross-Konno } \\
(\mathbf{n}=\mathbf{1 3})\end{array}$ & $\begin{array}{l}\text { Control } \\
(n=12)\end{array}$ & $\begin{array}{c}P \\
\text { value }\end{array}$ \\
\hline \multicolumn{5}{|l|}{ Circumferential strain } \\
\hline \multicolumn{5}{|l|}{ Left ventricle } \\
\hline Basal region global & $17.1 \pm 4.5$ & $17.2 \pm 3.8$ & $19.4 \pm 3.1$ & .195 \\
\hline Endocardial & $19.7 \pm 4.3$ & $19.1 \pm 4.2$ & $21.6 \pm 3.3$ & .324 \\
\hline Epicardial & $14.8 \pm 3.1$ & $13.0 \pm 4.2$ & $16.7 \pm 3.3$ & .065 \\
\hline $\begin{array}{l}\text { Midlevel region } \\
\text { global }\end{array}$ & $17.5 \pm 3.0$ & $17.4 \pm 2.8$ & $18.2 \pm 2.2$ & .744 \\
\hline Endocardial & $19.9 \pm 3.3$ & $19.5 \pm 3.9$ & $20.5 \pm 2.2$ & .778 \\
\hline Epicardial & $14.9 \pm 2.5$ & $15.6 \pm 2.8$ & $16.3 \pm 2.4$ & .429 \\
\hline \multicolumn{5}{|l|}{ Right ventricle } \\
\hline $\begin{array}{c}\text { Basal region } \\
\text { global }\end{array}$ & $13.0 \pm 4.0$ & $11.8 \pm 3.5$ & $13.1 \pm 3.1$ & .609 \\
\hline Endocardial & $14.1 \pm 4.3$ & $12.6 \pm 4.1$ & $15.0 \pm 3.6$ & .425 \\
\hline Epicardial & $12.2 \pm 2.8$ & $10.8 \pm 2.8$ & $11.9 \pm 3.0$ & .416 \\
\hline \multicolumn{5}{|l|}{ Longitudinal strain } \\
\hline \multicolumn{5}{|l|}{ Left ventricle } \\
\hline Global & $13.1 \pm 2.8^{*}$ & $13.7 \pm 3.4^{*}$ & $17.5 \pm 2.7$ & .002 \\
\hline Endocardial & $14.1 \pm 3.0^{*}$ & $14.5 \pm 3.7 \dagger$ & $18.2 \pm 2.6$ & .006 \\
\hline Epicardial & $12.1 \pm 2.7 \dagger$ & $12.7 \pm 2.9$ & $15.6 \pm 3.1$ & .010 \\
\hline \multicolumn{5}{|l|}{ Right ventricle } \\
\hline Global & $16.9 \pm 4.2$ & $17.6 \pm 4.6$ & $20.3 \pm 4.9$ & .129 \\
\hline Endocardial & $17.9 \pm 4.3$ & $18.4 \pm 4.5$ & $21.5 \pm 5.4$ & .122 \\
\hline Epicardial & $15.5 \pm 3.8$ & $15.9 \pm 4.1$ & $18.3 \pm 5.0$ & .266 \\
\hline
\end{tabular}

Values are presented as mean \pm standard deviation. Strain data are expressed as negative percent values. ${ }^{*} P<.01$ with respect to control group. $\dagger P<.05$.

strain. There were no differences in RV longitudinal strain metrics.

\section{Mechanical Dyssynchrony Analysis}

A summary of mechanical dyssynchrony results are depicted in Table 3 and Figure 3. When considering the LV global myocardium, patients who underwent a RossKonno procedure experienced significantly higher intraventricular mechanical dyssynchrony when compared with Ross and control groups (both $P$ values $<.01$ ). Mechanical dyssynchrony in the Ross-Konno group was increased in the septal region when compared with both Ross and control groups (both $P$ values $<.01$ ). With regard to mechanical dyssynchrony within the LV free wall, only the Ross-Konno group had increased dyssynchrony compared with controls $(P<.05)$. However, evaluation of the individual LV short-axis regions for mechanical dyssynchrony did not reveal significant changes among the groups. Lastly, interventricular mechanical dyssynchrony between RV and $\mathrm{LV}$ was increased in patients who underwent Ross operation when compared with the control group $(P<.05)$, and also in the Ross-Konno group when compared with the control group $(P<.01)$.

To explore the negative influence on biventricular mechanics, we correlated mechanical intraventricular and 

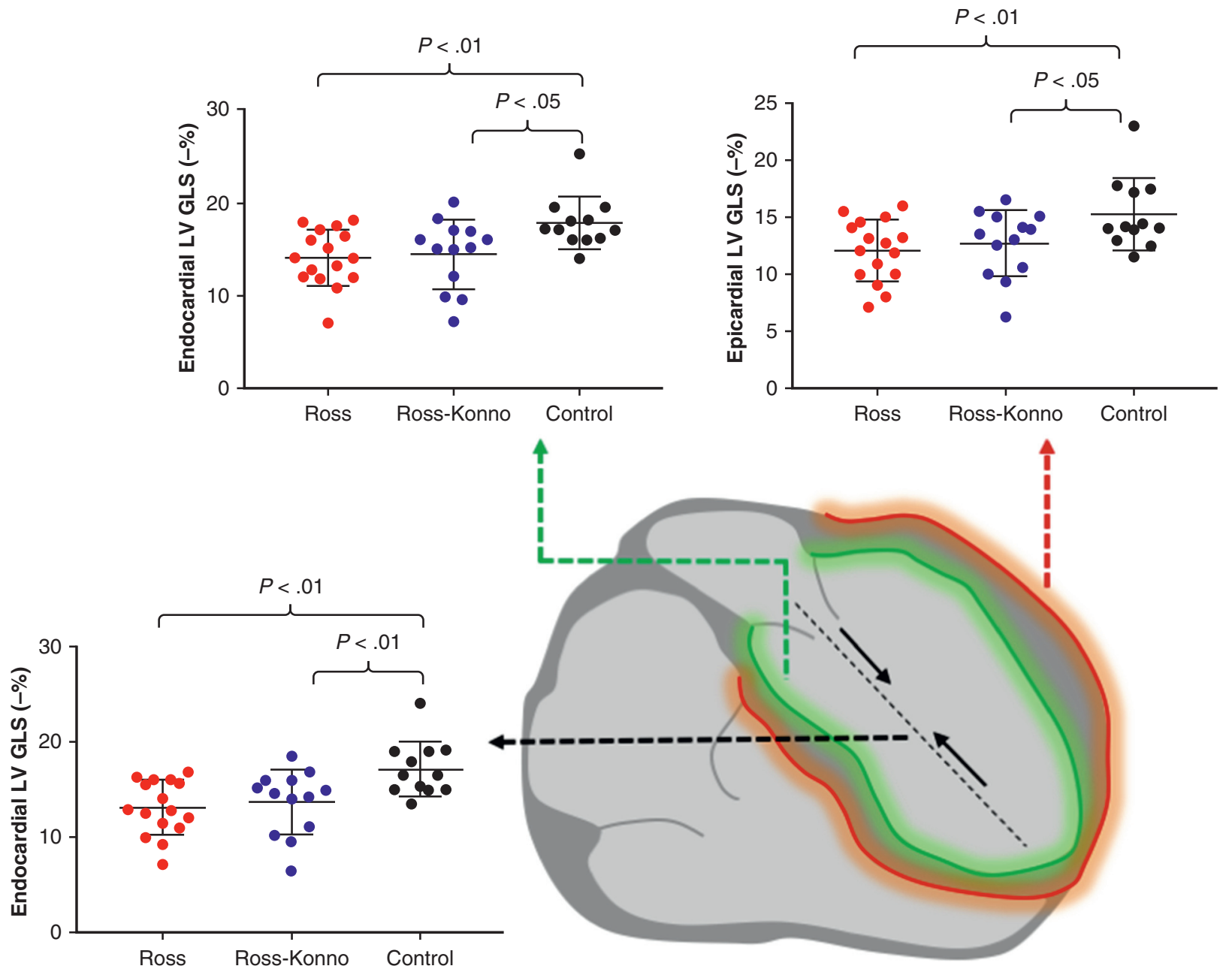

FIGURE 2. Summary of LV global longitudinal strain metrics. Patients who underwent Ross (red dots) or Ross-Konno (blue dots) procedures presented with reduced global longitudinal strain (LV GLS) along with its endocardial and epicardial components. Black middle horizontal lines represent the median values, with upper and lower lines representing the upper and lower quartiles, respectively. $L V G L S$, Left ventricle global longitudinal strain.

TABLE 3. Mechanical dyssynchrony, by subgroup

\begin{tabular}{|c|c|c|c|c|}
\hline Dyssynchrony & $\begin{array}{c}\text { Ross } \\
(\mathbf{n}=16)\end{array}$ & $\begin{array}{c}\text { Ross-Konno } \\
(\mathbf{n}=13)\end{array}$ & $\begin{array}{l}\text { Control } \\
(n=12)\end{array}$ & $\begin{array}{c}P \\
\text { value }\end{array}$ \\
\hline Global myocardium (ms) & $48 \pm 11^{*}$ & $71 \pm 26 \dagger$ & $40 \pm 11$ & $<.001$ \\
\hline Septum (ms) & $46 \pm 20^{*}$ & $77 \pm 40^{\dagger}$ & $37 \pm 16$ & .002 \\
\hline Free wall (ms) & $42 \pm 15$ & $59 \pm 29$ & $40 \pm 13$ & .045 \\
\hline Basal region (ms) & $48 \pm 16$ & $74 \pm 40$ & $41 \pm 16$ & .035 \\
\hline Septum (ms) & $42(26-83)$ & $76(22-98)$ & $20(17-49)$ & .078 \\
\hline Free wall (ms) & $39 \pm 13$ & $52 \pm 29$ & $42 \pm 20$ & .511 \\
\hline Midlevel region (ms) & $41 \pm 20$ & $51 \pm 20$ & $31 \pm 16$ & .052 \\
\hline Septum (ms) & $0(0-19)$ & $23(0-50)$ & $16(0-36)$ & .184 \\
\hline Free wall (ms) & $43 \pm 25$ & $52 \pm 25$ & $35 \pm 17$ & .183 \\
\hline $\begin{array}{l}\text { Right ventricle- } \\
\text { left ventricle } \\
\text { dyssynchrony (ms) }\end{array}$ & $62(34-75) \ddagger$ & $98(82-110) \dagger$ & $23(0-27)$ & $<.001$ \\
\hline
\end{tabular}

Values are presented as mean \pm standard deviation or as median (interquartile range). $* P<.05$ from Ross-Konno group. $\dagger P<.01$ with respect to control group. $\ddagger P<.05$. interventricular dyssynchrony with QRS duration (electrical dyssynchrony) and autograft regurgitation fraction. QRS duration correlated with global LV intraventricular dyssynchrony $(R=0.72 ; P<.001)$ (Figure 4$)$, and showed a positive trend with the degree of RV-LV interventricular dyssynchrony but did not reach significance $(R=0.33$; $P=.159)$. There was no significant association between the autograft regurgitation fraction and either intraventricular dyssynchrony $(R=0.17 ; P=.441)$ or RV-LV interventricular dyssynchrony $(R=0.28 ; P=.289)$.

\section{DISCUSSION}

Patients who undergo Ross and Ross-Konno operation have good long-term clinical outcomes with the major concern being the functional status of semilunar valve. The nature of the congenital lesions associated with aortic valve dysfunction along with both operative techniques 


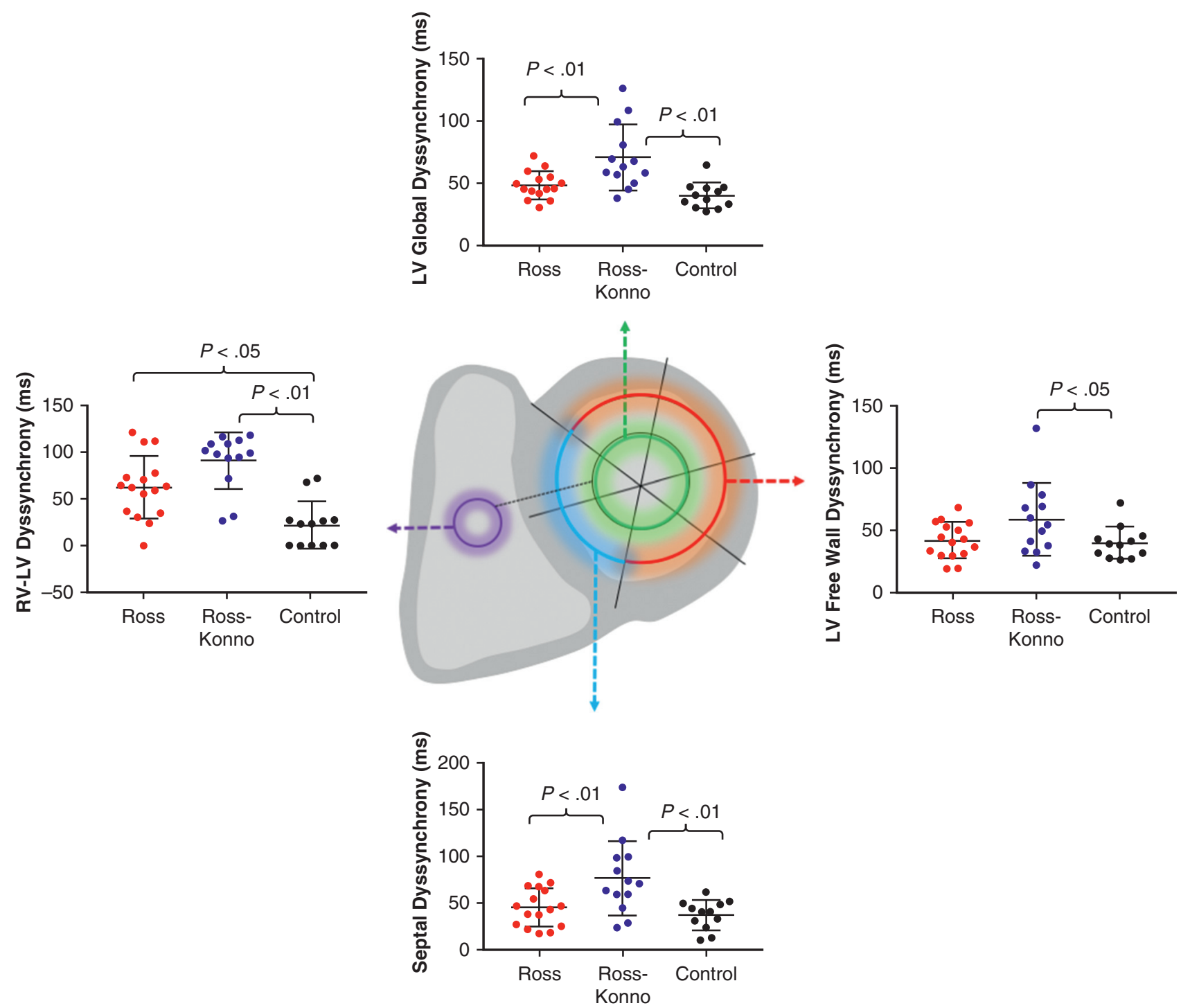

FIGURE 3. Summary of mechanical dyssynchrony results. Global myocardial left ventricle $(L V)$ intraventricular dyssynchrony (green) was increased in patients who underwent Ross-Konno (blue dots) operation with respect to both Ross (red dots) and control groups (black dots). Similarly, septal dyssynchrony (blue) was associated with Ross-Konno group. LV free-wall mechanical dyssynchrony (red) was increased in Ross-Konno group only with respect to control group. Right ventricle-LV interventricular dyssynchrony (purple) was increased in both Ross and Ross-Konno groups when compared with controls. Black middle horizontal lines represent the median values, with upper and lower lines representing the upper and lower quartiles, respectively. $R V$, Right ventricle.

predispose the conduction system to adverse remodeling or iatrogenic injury. Results of our study are as follows: patients who undergo Ross or Ross-Konno operation have normal biventricular functional status, yet reduced LV longitudinal strain; both Ross and Ross-Konno procedures are associated with long-term RV-LV interventricular dyssynchrony, patients who undergo the Ross-Konno procedure have increased LV intraventricular mechanical dyssynchrony; and finally, the degree of LV intraventricular dyssynchrony is associated with electrical dyssynchrony as measured by QRS duration and is independent of autograft function. Our results confirm previous findings regarding preserved biventricular function after Ross and
Ross-Konno operations with a minor reduction in deformation mechanics that can be typically surpassed by ventricular compensatory mechanisms such as myocardial thickening or increase in circumferential strain. ${ }^{20,26,27}$ The presence of the overall ventricular electromechanical dyssynchrony warrants long-term comprehensive followup of these patient populations.

\section{Preserved Biventricular Function With Reduction in Mechanical Strain}

Excellent long-term biventricular function has been previously reported in patients who underwent a Ross procedure. Puranik and colleagues ${ }^{26}$ reported normal cardiac 


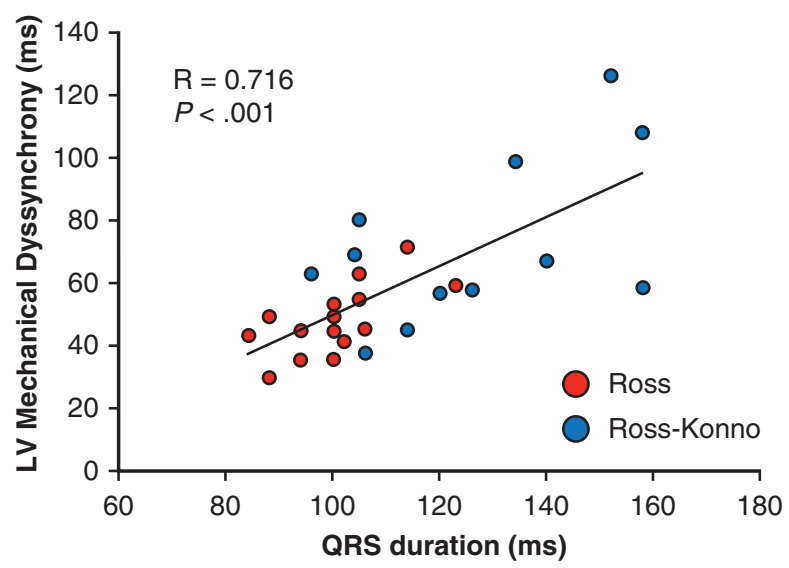

FIGURE 4. The electrical dyssynchrony component (QRS duration) correlated positively with left ventricle $(L V)$ intraventricular mechanical dyssynchrony suggesting the relationship between myocardial dyskinesia and compromised electrical conduction system.

MRI-derived biventricular ejection fraction, but $38 \%$ of patients had prominent scarring in the interventricular septum that was associated with septal dyskinesia. ${ }^{26}$ Additionally, Raedle-Hurst and colleagues ${ }^{20}$ reported results paralleled to ours describing echocardiography-derived reduced LV longitudinal strain with preserved ejection fraction in patients who underwent the Ross procedure. Both LV functional indices were independent of aortic regurgitation severity. Similarly, Hoashi and colleagues ${ }^{27}$ reported normalized contractile function of the $\mathrm{LV}$ as described by catheterization and echocardiography long after Ross-Konno procedures, albeit with reduced LV compliance as noticed by elevated end-diastolic pressures. Compromised diastolic function and reduced global longitudinal strain typically precede noticeable ventricular systolic performance and can occur without prominent reduction in the ejection fraction. ${ }^{28}$ This is primarily due to the anatomic location of longitudinally oriented myocardial fibers located within the subendocardial portion of the ventricle, which is most susceptible to myocardial injury. Stokke and colleagues ${ }^{29}$ recently provided a good explanation of compensatory methods responsible for preserved LV pump function in the setting of compromised LV longitudinal strain. The mathematic model proposed by Stokke and colleagues $^{29}$ showed that geometric effects represented by myocardial thickening can compensate for the loss in longitudinal and circumferential strain early in the disease process, indicating that early systolic dysfunction can be present without a major change in ejection fraction. Consequently, the reduced LV global longitudinal strain in patients who underwent Ross and Ross-Konno procedures suggests that chronic long-term myocardial remodeling might be present and should be monitored using sensitive mechanical deformation indices.

\section{Electromechanical Dyssynchrony}

The presence of mechanical intra- and interventricular dyssynchrony has been widely recognized in patients with congenital heart disease. Particularly, lesions associated with conotruncal abnormalities and ventricular septal defects have been shown to cause various degrees of mechanical dyssynchrony associated with poor contractile function. ${ }^{14,30}$ In our study, patients who underwent a Ross-Konno operation revealed LV-specific intraventricular dyssynchrony. The mismatch between contractile dynamics among various myocardial regions results in irreversibly wasted work generated by myocardium that elevates overall afterload on the LV. Russell and colleagues ${ }^{31}$ described that introduction of the left-bundle-branch block and mechanical dyssynchrony can nearly triple the amount of wasted myocardial work per cardiac cycle, with the septal region being out-of-phase with the LV free wall myocardium; that is, septal myocardial fibers undergoing premature shortening while the LV free wall fibers are still stretching and contribute to overall contraction. Indeed, our results imply that interventricular septal mechanics are predominantly influenced when compared with the LV free wall. However, the causality behind electromechanical coupling in patients who underwent Ross-Konno operation can be multifactorial and will require a larger patient population with more uniform congenital heart disease diagnoses to assess independently the influence of surgery, ventricular septal defects, and electrical dyssynchrony on the overall myocardial remodeling and mechanical performance. Furthermore, the very late outcomes after Ross-Konno operation should be assessed with respect to the electromechanical dyssynchrony to determine whether its presence is associated with negative clinical outcomes. Given that electrical dyssynchrony and compromised ventricular function are recognized comorbidities in patients undergoing Ross or Ross-Konno operations, we speculate that electromechanical evaluation using cardiac MRI might help with identification of suitable candidates for cardiac resynchronization therapy.

Contrary to the LV-isolated intraventricular dyssynchrony observed in the Ross-Konno group, RV-LV interventricular dyssynchrony was present in both Ross and Ross-Konno patients. The effect and presence of RV-LV interventricular dyssynchrony in patients with congenital heart disease is a less-explored phenomenon and has been preferentially described in association with right heart failure..$^{10,11,32}$ The typical scenario being a prolonged RV contraction period (myocardial shortening) due to impaired RV function and increased pulmonary afterload. This phenomenon was also observed in our study. In all considered patients, the RV time-to-peak was longer than the LV time-to-peak. Consequently, the RV myocardium is still in the contractile phase when the mitral valve opens 
and LV undergoes early diastolic filling. As a result, the LV function can also be compromised due to abnormal loading conditions. Our results suggest that there is a trend between electrical dyssynchrony and interventricular phase mismatch but further longitudinal studies are required to investigate whether there is a direct association between electrical and mechanical physiologic components, or whether the is RV undergoing an afterload-adaptive myocardial remodeling.

\section{Study Limitations}

This was a small single-center retrospective study, which limited our ability to perform specific patient group subanalysis with respect to the original congenital heart lesion or type of bundle branch block. Secondly, cardiac MRI protocols, in general, provide lower temporal resolution compared with echocardiographic studies using speckle-tracking methods, which could affect time-to-peak measurements and overall mechanical dyssynchrony analysis. However, MRI has higher spatial resolution, and enables comprehensive volumetric and function analysis from a single protocol. Additionally, we attempted to mitigate this error by uniform application of our postprocessing algorithm for each case. Thirdly, this was a cross-sectional study of patients with heterogenous congenital lesions leading to either Ross or Ross-Konno operations, and consequently we could not explore the longitudinal aspect of the LV remodeling with respect to the actual operation and LV-aortic coupling. Participants considered in this study represent our population of survivors of Ross and Ross Konno operations undergoing follow-up within our network of care. All such adolescent and adult patients within our network undergo interval cardiac MRI for the evaluation of conduit and RV function as recommended by adult congenital heart disease guidelines. ${ }^{33}$ Our future efforts will focus on the comprehensive longitudinal evaluation of electromechanical dyssynchrony pre- and postsurgery to better understand the underlying role of specific congenital lesions and surgical techniques.

\section{CONCLUSIONS}

Long-term MRI follow-up of patients after Ross and Ross-Konno procedures shows reduced LV global longitudinal strain suggesting chronically increased afterload, and RV-LV interventricular dyssynchrony despite preserved biventricular ejection fraction and normal autograft function. Additionally, the Ross-Konno operation is associated with impaired LV intraventricular mechanics and electrical dyssynchrony. Mechanical deformation indices might be better measures of long-term ventricular performance in this patient population. Future longitudinal studies with more uniform patient populations are required to provide better understanding of the electromechanical interplay following Ross and Ross-Konno operations and its effect on long-term clinical outcomes.

\section{Conflict of Interest Statement}

Authors have nothing to disclose with regard to commercial support.

The authors thank Neil Wilson for helping with the preparation of the manuscript.

\section{References}

1. David TE, Ouzounian M, David CM, Lafreniere-Roula M, Manlhiot C. Late results of the Ross procedure. J Thorac Cardiovasc Surg. 2019;157:201-8.

2. Kouchoukos NT, Masetti P, Nickerson NJ, Castner CF, Shannon WD, DávilaRomán VG. The Ross procedure: long-term clinical and echocardiographic follow-up. Ann Thorac Surg. 2004;78:773-81.

3. Brown JW, Ruzmetov M, Vijay P, Rodefeld MD, Turrentine MW. The RossKonno procedure in children: outcomes, autograft and allograft function, and reoperations. Ann Thorac Surg. 2006;82:1301-6.

4. Hraska V, Krajci M, Haun C, Ntalakoura K, Razek V, Lacour-Gayet F, et al. Ross and Ross-Konno procedure in children and adolescents: mid-term results. Eur J Cardiothorac Surg. 2004;25:742-7.

5. Ruzmetov M, Geiss DM, Shah JJ, Buckley K, Fortuna RS. The Ross-Konno is a high-risk procedure when compared with the Ross operation in children. Ann Thorac Surg. 2013;95:670-5.

6. Pastuszko P, Spray TL. The Ross/Konno procedure. Oper Tech Thorac Cardiovasc Surg. 2002;7:195-206.

7. Muresian H. The Ross procedure: new insights into the surgical anatomy. Ann Thorac Surg. 2006;81:495-501.

8. Jing L, Wehner GJ, Suever JD, Charnigo RJ, Alhadad S, Stearns E, et al. Left and right ventricular dyssynchrony and strains from cardiovascular magnetic resonance feature tracking do not predict deterioration of ventricular function in patients with repaired tetralogy of Fallot. J Cardiovasc Magn Reson. 2016;18:49.

9. Jing L, Haggerty CM, Suever JD, Alhadad S, Prakash A, Cecchin F, et al. Patients with repaired tetralogy of Fallot suffer from intra-and inter-ventricular cardiac dyssynchrony: a cardiacmagnetic resonance study. Eur Heart J Cardiovasc Imaging. 2014;15:1333-43.

10. Hill AC, Maxey DM, Rosenthal DN, Siehr SL, Hollander SA, Feinstein JA, et al. Electrical and mechanical dyssynchrony in pediatric pulmonary hypertension. $J$ Heart Lung Transplant. 2012;31:825-30.

11. Schäfer M, Collins KK, Browne LP, Ivy DD, Abman S, Friesen R, et al. Effect of electrical dyssynchrony on left and right ventricular mechanics in children with pulmonary arterial hypertension. J Heart Lung Transplant. 2018;37:870-8.

12. Nagueh SF. Mechanical dyssynchrony in congestive heart failure. Diagnostic and therapeutic implications. J Am Coll Cardiol. 2008;51:18-22.

13. Badagliacca R, Reali M, Poscia R, Pezzuto B, Papa S, Mezzapesa M, et al. Right intraventricular dyssynchrony in idiopathic, heritable, and anorexigen-induced pulmonary arterial hypertension. JACC Cardiovasc Imaging. 2015;8:642-52.

14. Motonaga KS, Dubin AM. Cardiac resynchronization therapy for pediatric patients with heart failure and congenital heart disease: a reappraisal of results. Circulation. 2014;129:1879-91.

15. Janoušek J, Kovanda J, Ložek M, Tomek V, Vojtovic P, Gebauer R, et al. Pulmonary right ventricular resynchronization in congenital heart disease: acute improvement in right ventricular mechanics and contraction efficiency. Circ Cardiovasc Imaging. 2017;10:1-9.

16. Bockoven JR, Wernovsky G, Vetter VL, Wieand TS, Spray TL, Rhodes LA. Perioperative conduction and rhythm disturbances after the Ross procedure in young patients. Ann Thorac Surg. 1998;66:1383-8.

17. Pasquali SK, Marino BS, Kaltman JR, Schissler AJ, Wernovsky G, Cohen MS, et al. Rhythm and conduction disturbances at midterm follow-up after the ross procedure in infants, children, and young adults. Ann Thorac Surg. 2008;85:2072-8.

18. Normand C, Linde C, Singh J, Dickstein K. Indications for cardiac resynchronization therapy: a comparison of the major international guidelines. JACC Heart Fail. 2018;6:308-16.

19. Hui W, Slorach C, Dragulescu A, Mertens L, Bijnens B, Friedberg MK. Mechanisms of right ventricular electromechanical dyssynchrony and mechanical inefficiency in children after repair of tetralogy of Fallot. Circ Cardiovasc Imaging. 2014; 7:610-8. 
20. Raedle-Hurst TM, Hosse M, Hoffmann S, Abdul-Khaliq H, Schäfers HJ. Ventricular performance assessed by 2-dimensional strain analysis after ross operation versus aortic valve reconstruction. Ann Thorac Surg. 2013;96:1567-73.

21. Grotenhuis HB, Westenberg JJM, Doornbos J, Kroft LJ, Schoof PH, Hazekamp MG, et al. Aortic root dysfunctioning and its effect on left ventricular function in Ross procedure patients assessed with magnetic resonance imaging. Am Heart J. 2006;152:975.e1-8.

22. Taylor RJ, Moody WE, Umar F, Edwards NC, Taylor TJ, Stegemann B, et al. Myocardial strain measurement with feature-tracking cardiovascular magnetic resonance: normal values. Eur Heart J Cardiovasc Imaging. 2015;16:871-81.

23. Vo HQ, Marwick TH, Negishi K. MRI-derived myocardial strain measures in normal subjects. JACC Cardiovasc Imaging. 2018;11(2 Part 1):196-205.

24. Davignon A, Rautaharju P, Boisselle E, Soumis F, Mégélas M, Choquette A. Normal ECG standards for infants and children. Pediatr Cardiol. 1980;1:123-31.

25. Surawicz B, Childers R, Deal BJ, Gettes LS. AHA/ACCF/HRS recommendations for the standardization and interpretation of the electrocardiogram. Part III: intraventricular conduction disturbances a scientific statement from the American Heart Association Electrocardiography and Arrhythmias Committee. J Am Coll Cardiol. 2009;53:976-81.

26. Puranik R, Tsang VT, Broadley A, Nordmeyer J, Lurz P, Muthialu N, et al. Functional outcomes after the Ross (pulmonary autograft) procedure assessed with magnetic resonance imaging and cardiopulmonary exercise testing. Heart. 2010;96:304-8.

27. Hoashi T, Kagisaki K, Kurosaki K, Shiraishi I, Yagihara T, Ichikawa H. Late left ventricular function after successful Ross-Konno operation. Ann Thorac Surg. 2013;96:196-201.
28. Flachskampf FA, Biering-Sorensen T, Solomon SD, Duvernoy O, Bjerner T, Smiseth OA. Cardiac imaging to evaluate left ventricular diastolic function. JACC Cardiovasc Imaging. 2015;8:1071-93.

29. Stokke TM, Hasselberg NE, Smedsrud MK, Sarvari SI, Haugaa KH, Smiseth OA et al. Geometry as a confounder when assessing ventricular systolic function: comparison between ejection fraction and strain. J Am Coll Cardiol. 2017;70: 942-54.

30. Van Der Hulst AE, Delgado V, Blom NA, van de Veire NR, Schalij MJ, Bax JJ, et al. Cardiac resynchronization therapy in paediatric and congenital heart disease patients. Eur Heart J. 2011;32:2236-46.

31. Russell K, Eriksen M, Aaberge L, Wilhelmsen N, Skulstad H, Gjesdal O, et al Assessment of wasted myocardial work: a novel method to quantify energy loss due to uncoordinated left ventricular contractions. Am J Physiol Heart Circ Physiol. 2013;305:H996-1003.

32. Nagao M, Yamasaki Y, Yonezawa M, Matsuo Y, Kamitani T, Yamamura K, et al Interventricular dyssynchrony using tagging magnetic resonance imaging predicts right ventricular dysfunction in adult congenital heart disease. Congenit Heart Dis. 2015;10:271-80.

33. Stout KK, Daniels CJ, Aboulhosn JA, Bozkurt B, Broberg CS, Colman JM, et al 2018 AHA/ACC guideline for the management of adults with congenital heart disease. J Am Coll Cardiol. 2018;18:S0735-1097.

Key Words: Ross operation, Ross-Konno operation, electromechanical dyssynchrony

Readers who found these articles interesting may also like to read the following papers found in recent and future issues of our sister publications, Seminars in Thoracic and Cardiovascular Surgery and Operative Techniques in Thoracic and Cardiovascular Surgery!

\section{Congenital: Aortic Valve}

EXPERT REVIEW: Aortic Valve Interventions in Pediatric Patients. Ismail Bouhout. Semin Thoracic Surg 2018: In press

Commentary: Aortic Valve Interventions in Children: Still Only Scratching the Surface. Patrick O. Myers. Semin Thoracic Surg 2018: In press

ORIGINAL MANUSCRIPT: Quality of life among patients with congenital heart disease after valve replacement. Hanna Pragt. Semin Thoracic Surg 2019: In press 